\title{
A NECESSIDADE DE SE EFETIVAR O DEVER CONSTITUCIONAL À BOA GOVERNANÇA PÚBLICA NO ATUAL ESTADO DEMOCRÁTICO DE DIREITO BRASILEIRO ${ }^{1}$
}

\begin{abstract}
José Eduardo Sabo Paes
Doutor pela Universidade Complutense de Madri. Professor da Pós-Graduação Stricto Sensu em Direito da Universidade Católica de Brasília (UCB). Coordenador Geral do Núcleo de Estudos e Pesquisas Avançadas do Terceiro Setor (NEPATS). Procurador de Justiça do MPDFT. E-mail: sabo@mpdf.gov.br.
\end{abstract}

\section{Severiano José Costandrade de Aguiar}

Conselheiro do Tribunal de Contas do Estado do Tocantins. Bacharel em Direito pela Universidade Federal do Piauí. Pós-Graduado em Administração da Educação pela Universidade de Brasília (UnB), em Direito Processual Civil pela Universidade Tiradentes e em Estudos de Política e Estratégia pela ADESG/UFT. Atualmente, é Doutorando em Ciências Jurídicas e Sociais pela Universidad del Museo Social Argentino-UMSA. Ocupou diversos cargos de relevância no Estado do Tocantins, entre eles o de secretário de Desenvolvimento Comunitário de Palmas, coordenador do curso de Ciências Contábeis da Fundação Universidade do Tocantins (Unitins), defensor público e procurador do Estado, entre outros. A partir de 2000, passou a ocupar, cumulativamente, os cargos de presidente do Instituto Social Divino Espírito Santo (Prodivino) e de secretário estadual do Trabalho e Ação Social.

\section{Júlio Edstron S. Santos}

Doutorando em Direito pelo Centro Universitário de Brasília - UniCEUB. Mestre em Direito Internacional Econômico pela UCB/DF. Professor do IDASP/Palmas (TO). Membro do Núcleo de Estudos e Pesquisas Avançadas do Terceiro Setor (NEPATS) da UCB/DF, e do grupo de pesquisa Políticas Públicas e Juspositivismo, Jusmoralismo e Justiça Política do UniCEUB. E-mail: edstron@yahoo.com.br.

Resumo: 0 problema de pesquisa enfrentado neste artigo acadêmico é: existe um dever fundamental de se implementar a boa governança pública no Brasil? A discussão foi fulcrada no método hipotéticodedutivo e teve como base as técnicas cientificas da revisão bibliográfica e estudo de caso. Este artigo acadêmico teve por objetivo demonstrar a necessidade de aplicação do dever jurídico de

1 Pesquisa realizada e debatida no Núcleo de Estudos e Pesquisas Avançadas do Terceiro Setor (NEPATS) e apoiada pela Fundação Paiva Neto. 
implementação da boa governança pública, sob a égide do atual paradigma do Estado Democrático de Direito. Para tanto, foram evidenciados sinteticamente a evolução do Estado de Direito, liberal e social, até o parâmetro que ainda está em construção. Em seguida apontou-se a diferença entre os direitos e deveres fundamentais e, por fim, foram explanados os problemas estruturais de corrupção que impedem a cristalização dos direitos essenciais. A conclusão extraída com base nas lições doutrinárias e casos reais é que se faz necessária a adoção de critérios que aprimorem a prestação de serviços públicos no Brasil.

Palavras-chave: Boa gestão pública. Deveres fundamentais. Estado Democrático de Direito.

Sumário: 1 Introdução - 2 O Estado Democrático de Direito: mudanças, deveres e desafios 2.10 dever fundamental e o Estado Democrático de Direito - 3 A necessidade de efetivação do dever fundamental de implementação de uma boa governança pública - 4 Considerações finais - Referências

Democracia é oportunizar a todos o mesmo ponto de partida. Quanto ao ponto de chegada, depende de cada um.

(Fernando Sabino)

\section{Introdução}

Desde os anos 2000 até o presente, o mundo presencia uma forte crise que se espraiou por vários países, inclusive, o Brasil. Há um sério questionamento sobre institutos e instituições que estavam consolidados e, também, em relação à democracia e no tocante à própria continuidade do Estado. Por causa da carência de prestação dos serviços públicos foram identificados assombrosos casos de corrupção nos âmbitos interno e internacional, levando a um consequente tolhimento da efetivação dos direitos, deveres e garantias fundamentais.

Assim, a problematização enfrentada neste ensaio acadêmico é se existe no Brasil um dever fundamental de se efetivar a boa gestão pública. Para tanto, foi utilizado o método hipotético dedutivo, comprovando-se o alinhamento entre as hipóteses e as conjecturas analisadas no presente texto. Do mesmo modo, foram utilizados métodos de revisão bibliográfica e estudo dos casos necessários para a elucidação de nossa problematização.

O presente texto versou acerca da necessária efetivação da boa governança pública, ou seja, que haja o fiel cumprimento das previsões constitucionais e legais referentes à Administração Pública e à aplicação das práticas recomendadas pelos instrumentos do accountability, compliance e governança, entre os quais o princípio fundamental da eficiência, mediante aplicação dos métodos científicos da revisão bibliográfica e estudo de caso. 
Salientou-se que virtualmente ninguém se coloca em contraposição ao exercício da boa governança pública. Contudo, a sociedade assiste a variados casos em que isto não ocorre, causando sérios problemas para a efetivação dos direitos e garantias dos cidadãos. Portanto, é necessário que haja uma constante aproximação entre a visão acadêmica e a prática de gestão pública.

Deste modo, ao pontuar o objetivo acadêmico deste texto fez-se uma (re) construção dos paradigmas estatais, perpassando sinteticamente os modelos absolutistas, liberal, social e do Estado Democrático de Direito, com a indicação de suas principais características. Além disso, ressalta-se a construção destes modelos democráticos, por não terem ocorrido de forma linear, mas que, porém, nascem das necessidades de cada sociedade por causa de seus próprios problemas.

Em seguida, foram analisados os principais conceitos dos direitos fundamentais, sua alta hierarquia e essencialidade, inclusive este trabalho demonstra os valores pecuniários investidos pela União em cultura, educação, saúde e segurança pública ao inferir que ocorreu indicação e execução orçamentária de vultosas somas de dinheiro público. Contudo, também há problemas de administração e gestão públicas, impedindo a efetivação dos direitos e garantias fundamentais, suscitando a percepção da necessidade de se efetivar a boa governança pública.

Foram expostos os basilares conceitos doutrinários nacionais e internacionais sobre os "deveres fundamentais", comprovando-se que, apesar da pouca atenção que recebem da academia, tal como lecionaram os autores indicados no texto, eles estão no mesmo patamar dos direitos e garantias previstos na Constituição, sendo, então, também essenciais para a construção do paradigma do Estado Democrático de Direito e consequentemente das atuais previsões jurídicas.

Apontamos as principais pesquisas nacionais e internacionais sobre a corrupção, sendo esta um fenômeno mundial de apropriação de recursos públicos que, segundo a Organização das Nações Unidas (ONU), alija a sociedade de trilhões de reais anualmente. Neste sentido, o Brasil tem uma posição de destaque no ranking de países mais corruptos do planeta, indicando-se que há necessidade de efetivação do dever fundamental à boa governança pública no Brasil.

Pelos problemas expostos, é necessário que a academia auxilie os poderes estatais constituídos nas pesquisas, que já se encontram estabelecidas sobre a aplicação de instrumentos eficazes, que evitam práticas de corrupção de forma efetiva, impedindo que recursos essenciais para a sociedade sejam desviados. A inquietação desta pesquisa se apresenta no sentido de analisar como os recursos desviados pela corrupção deveriam ser utilizados para efetivar os direitos e 
garantias fundamentais, como cultura, educação, saúde e segurança pública que, como se buscou apontar no texto, são essenciais.

Por fim, foi deixada de forma clara a ilação sobre a necessidade de se efetivar o dever fundamental à boa governança pública, com os cumprimentos dos preceitos constitucionais e legais, além da adoção de práticas focadas no accountability, compliance e governança, com o fortalecimento do Estado Democrático de Direito e a consolidação dos direitos e garantias fundamentais.

\section{Estado Democrático de Direito: mudanças, deveres e desafios}

Ao se instaurar a modernidade líquida, ${ }^{2}$ são identificadas crises em vários âmbitos da sociedade, entre eles os conflitos nas esferas econômica, financeira, política, social e humanística, sendo esta última culminada em uma percepção individualista e mecanicista dos aparelhos de Estado. Das crises se estabelecem no plano global reconhece-se que "vivemos tempos sombrios, tempos de incertezas, de crise de valores, de relativo abandono das conquistas e das obras que nos caracterizam como partícipes da civilização ocidental”, como lecionaram Horta e Salgado (2017, p. 84).

A situação de tensão é tão grave que também pode ser alinhavada com a intensa crise planetária descrita cientificamente pelo sociólogo polonês Zygmunt Bauman em sua obra Estado de Crise (2016), demonstrando que a ação estatal está cada vez mais questionada frente aos desafios modernos. Tal situação também é presente no Brasil, que no plano interno estabelece pressão na democracia e na República, já que há constante carência na efetivação dos direitos e garantias fundamentais, tal como é constatado doutrinariamente por Mounk (2019), ou ainda:

O que se associa à ideia de um déficit nas democracias diz respeito a uma alta desconfiança dos cidadãos nas instituições e uma elevada percepção de mau funcionamento da máquina pública. A oferta de bens e serviços públicos é prejudicada pela ineficiência, ineficácia e inefetividade das políticas públicas, por serviços públicos arcaicos e fortemente burocráticos, pela falta de profissionalização, treinamento e capacitação de servidores, pela corrupção sistêmica e por modelos de gestão pública que não percebam a capacidade da administração para adicionar valores públicos e sua conexão com o sistema político. Neste contexto, o conceito de governança foi ganhando corpo

BAUMAN, Zygmunt. Modernidade Liquida. Trad. Plínio Dentzien. Rio de Janeiro Zahar, 2011. 
como mecanismo de crítica aos modelos de gestão da New Public Management. (FILGUEIRA, 2018, p. 77)

$\mathrm{Na}$ sociedade brasileira recente, como esperado, esta conjuntura de necessidade de efetivação de proteção estatal não é diferente do plano global, sendo, inclusive, às vezes comparativamente mais grave por conta da existência de mais de cinquenta milhões de miseráveis, ou seja, estatisticamente uma entre quatro famílias brasileiras estavam na linha da pobreza no ano de 2017, segundo pesquisa do Instituto Brasileiro de Geografia e Estatística ${ }^{3}$ (IBGE).

Assim, a Administração Pública deve agir com cautela, mas, sobretudo com eficiência nos âmbitos político, econômico e mesmo jurídico, cumprindo o dever constitucional de se instaurar uma boa gestão pública que cumpra integralmente as previsões constitucionais e também as políticas públicas.

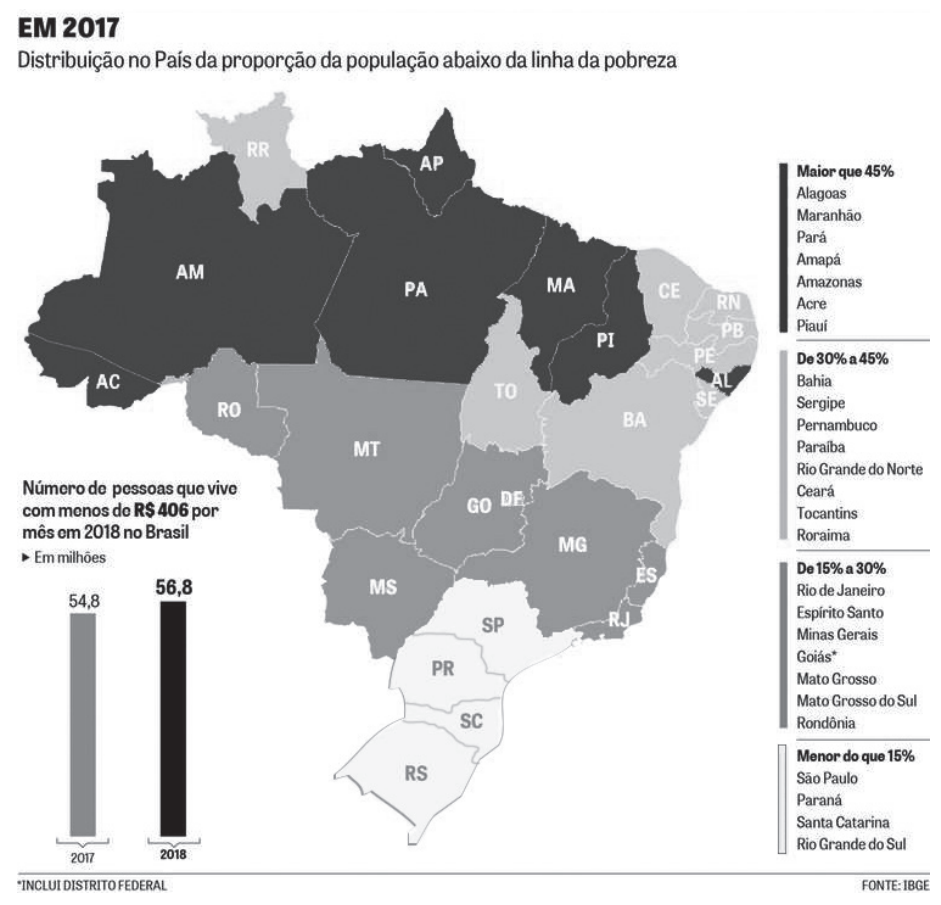

Salienta-se que este número de necessitados cresce a cada momento, por problemas internos como a escassez de recursos públicos para investimentos,

3 Pesquisa encontrada no site: http://agenciabrasil.ebc.com.br/economia/noticia/2017-12/ibge-brasiltem-14-de-sua-populacao-vivendo-na-linha-de-pobreza 
e externos como os fluxos de migrações forçadas que ocorrem com os cidadãos venezuelanos que se refugiam desenfreadamente em estados brasileiros como Roraima, o que deixa a impressão de um erro sintomático na maneira como se lida com as políticas sociais e migratórias, na gestão pública, nacional e internacional, tal como comprova o gráfico do próprio IBGE colacionado acima.

Frente a estes problemas é necessária a união de esforços da academia, agentes estatais e sociedade civil para a proposição de ideias e efetivação de resultados que sanem esta situação, afinal: "Faz escuro, mas eu canto por que amanhã vai chegar", como foi cantado pela intérprete Nara Leão (2019, p.1), deixando uma mensagem de otimismo típica dos brasileiros.

Neste sentido, o ano de 2019 é marcante para a história do Estado e do próprio Direito, já que se completam os cem anos da invulgar Constituição de Weimar ou, em alemão, Weimarer Verfassung, promulgada no dia 31 de julho de 1919, inaugurando na Europa o constitucionalismo social. Essencialmente, esta constituição buscava a concretização da igualdade material, através da prestação positiva de direitos e serviços pela Administração Pública, através da adoção de políticas e programas públicos, trazendo mudanças, deveres e desafios, por exemplo, o dever de se implantar uma boa governança pública, tal como se verificará adiante neste trabalho.

Uma nota histórica é que tanto a Constituição do México de 1917, quanto a alemã de Weimar, de 1919, avançaram na positivação dos direitos sociais. Contudo, em função da necessidade de efetivação desta dimensão jurídica, tanto no plano financeiro quanto da necessidade de negociações políticas para sua concretização, houve variados problemas de governabilidade e governança estatal, à sua época, sendo aqueles muito parecidos com os dilemas atuais, gerando a seguinte repercussão:

A América Latina contemporânea passa por um processo tão marcante de redefinição dos princípios que devem preponderar nas Constituições de seus países que só se compara a outros dois momentos prévios de sua história: a fundação dos estados independentes na região durante o século XX e a promulgação de novas Constituições que incluíram os direitos coletivos relacionados ao mundo do trabalho e que incorporaram a ideia de "função social" durante a metade do século XX (MOTA, 2017, p. 77).

Por conseguinte, cabe lembrar que, do ponto de vista da centralização estatal, houve quatro grandes paradigmas, sendo o primeiro o absolutismo, marcado pela vontade do governante, à sua época legitimado pela vontade divina, tal como explicou Martin van Creveld (2004), sendo sintetizado pela máxima de 
Luís XIV, conhecido como o Rei Sol, para quem: “L'État c'est moi”. Outra lembrança histórica daquele momento é que a ação estatal foi identificada como um Estado de Polícia, dado o seu alto grau de invasão na esfera privada, como lecionou Arruda Neto (2015).

Pressupõem-se a indicação que tal pensamento absolutista demonstrou para a aspiração real que, em regra, se tornava lei ou ainda nota doutrinária "o sentido próprio de Estado absoluto como aquele em que se opera a máxima concentração de poder no Rei (sozinho ou com os seus ministros)" (MIRANDA, 2009, p. 30). 0 absolutismo como forma de governo não se adaptou aos parâmetros do Estado de Direito, já que a vontade do governante, quase onipresente, se sobrepunha a todas as funções estatais como Legislativo e Judiciário, lembrando o exemplo histórico da imposição do Poder Moderador na Constituição brasileira de 1824, que se postava acima das demais estruturas orgânicas estatais.

Em consequência, as revoluções oitocentistas, principalmente a estadunidense (1787) e francesa (1789), causaram ruptura do sistema milenar feudal e do absolutismo. Em tal contexto histórico, instaurou-se um modelo de Estado de Direito calcado no império da lei e no absenteísmo estatal, resultando em um novo paradigma, que assim pode ser abreviado: "el Estado aparece como el servidor, rigorosamente controlado, de la sociedade" (SCHMITT, 1975, p. 145).

Desta maneira, naquela fase observou-se uma mudança estrutural, tendo em vista que o Estado e a Administração Pública passaram a existir na função de elaborar políticas públicas que protegessem e incentivassem os cidadãos e, principalmente, para reconhecer e consolidar direitos e garantias essenciais. Sobretudo, com os necessários controles internos e internacionais, tal como ensinado por José Geraldo de Souza Junior (2006).

Nesta linha de pensamento, duas marcas do modelo estatal liberal se destacam: a não interferência do Estado na esfera privada; e a prevalência da legislação sobre a vontade da lei. Isto provoca o preceito jurídic hoje amplamente positivado de que: "ninguém será obrigado a fazer ou deixar de fazer alguma coisa senão em virtude de lei"4 (BRASIL, 2019, p. 3).

Sintetiza-se que "o constitucionalismo dos séculos XVIII e XIX volta-se basicamente para a garantia formal da liberdade" (SILVA, 2014, p. 68). Contudo, apesar dos avanços trazidos pelo paradigma ${ }^{5}$ do Estado Liberal de Direito, tal como a instauração da igualdade formal, perpetua-se um alto grau de desigualdades

4 Foi utilizado como referência a Constituição da República Federativa do Brasil de 1988, contudo, há de se lembrar que em todas as constituições republicanas houve a reprodução deste preceito.

5 Paradigma foi utilizado no sentido teorizado por Thomas Kuhn, que se refere ao modelo instaurado em determinado local e em certa época, como bem descrito na obra Estrutura das Revoluções Científicas. 
social e econômica, ao acarretar um quadro preocupante de exclusão social, já que as diferenças geradas durante os séculos do absolutismo foram alargadas.

Historicamente, os quadros de desigualdade e exclusão social foram agravados pelas duas Grandes Guerras Mundiais que destruíram a estrutura física básica da África, Ásia e Europa, impondo uma mudança na postura de participação do Estado ao forçar uma alteração no paradigma constitucional, que avançou na positivação dos direitos e garantias sociais, tais como saúde, educação e moradia ou, ainda segundo lição doutrinária:

El Estado Social, fenômeno coincidente en todos los países en que se dan determinadas condiciones económicas, sociales y culturales, aparece como resultado del colapso del Estado bugués liberal decimonónico, para transformarse en un entre programático al que cabría atribuir una serie de competências manifiestamente superior a las que ejercia su prececessor. (CONDE; AUSINA, 2014, p. 56).

Em decorrência do quadro de exclusão social e da necessidade de participação do Estado na reconstrução dos países por causa dos danos oriundos das guerras, se inaugurou o modelo denominado Estado Social de Direito, que visa a maior ação estatal, mediante a participação da Administração Pública em todas as suas esferas, na construção de condições do estabelecimento da igualdade material, ou seja, da cristalização de condições que possibilitem o acesso a direitos essenciais como saúde, educação e segurança a todas as pessoas, bem como demonstra a seguinte síntese doutrinária sobre a ideia central deste modelo de atuação estatal:

\footnotetext{
Estado social será, no entanto, produto de grande efervescência de ideias, nas mais das vezes contraditórias (como é contraditório são os diversos tipos de Estado social, uns mais, outros menos Estado de Direito), mas girando no entorno da noção de igualdade. (HORTA, 2011, p. 127).
}

Neste sentido, se reconhece que o Estado de Direito estreou a prevalência da lei sobre a vontade pessoal ao superar o absolutismo do ancien régime. 0 paradigma social assegurou a igualdade de condições e o Estado Democrático de Direito (EDD) por meio da concretização de leis, de procedimentos de participação que incluem a população nos critérios de adoção e aplicação das normas jurídicas, tal como propugnou Haberle (2012).

Porém, registra-se que a evolução do Estado de Direito não deve ser entendida como uma construção linear, já que é marcada por movimentos pendulares e 
consagrada pelo reconhecimento das necessidades sociais a cada momento histórico, impondo até à Administração Pública limites e extensões no âmbito constitucional de sua atuação.

O EDD é um paradigma em construção, seus contornos ainda não estão totalmente definidos, já que ele é marcado principalmente pelo dever de se fazer o reconhecimento da cidadania e dignidade da pessoa humana na qualidade de alicerces de toda a ação estatal, bem como é distinguido por dificuldades consensuais, pois, atualmente, a sociedade é complexa, antagônica e mesmo líquida, como teorizou Bauman (2003), já que se amolda às mais variadas situações.

Um dos avanços científicos do Estado Democrático de Direito é o entendimento de que é um meio para a efetivação da cidadania participativa e inclusiva, com a inserção das pessoas nos processos de tomadas de decisão e geração de resultados das atividades públicas, tais como os conselhos representativos e, desta maneira, atuam na fixação dos direitos e garantias fundamentais, ou como: “uma chave interpretativa do Direito Constitucional democrático contemporâneo e suporte teórico para a interpretação e aplicação adequadas do Direito Constitucional brasileiro vigente" (CATTONI, 2002, p. 25).

A efetivação dos direitos fundamentais sob a égide do EDD é um dos desafios da atualidade, posto que grupos sociais buscam a primazia da distribuição de recursos financeiros cada vez mais escassos, ainda que sejam investidos vultosos valores oriundos do erário, como demonstra o quadro à frente, baseado em informações públicas divulgadas pelo Sistema Integrado de Planejamento e Orçamento (SIOP), incluindo os dados até o final do ano de 2018. No quadro, aponta-se os anos de 2014 a 2018 nos gastos efetivados nos investimentos com direitos fundamentais da cultura, educação, saúde e segurança pública, chegando a exatos $\mathrm{R} \$$ 1.105.560.612.513,25 (um trilhão, cento e cinco bilhões, quinhentos e sessenta milhões, seiscentos e doze mil, quinhentos e treze reais e vinte e cinco centavos).

Adianta-se que, apesar do alto valor executado no orçamento e dos consideráveis avanços, estes direitos ainda necessitam de efetivação no Estado brasileiro, configura-se aí a sensação de que a Administração Pública ainda precisa ser mais eficiente e cumprir os fundamentos da boa gestão pública.

Do Estado Absolutista ao contexto atual houve mudanças significativas ocasionadas por fatores como a mundialização (SILVA, 2015) e globalização (BAUMAN, 1999), que proporcionaram avanços nas áreas de telecomunicações e transportes, mas também desafios como o aumento da volatilidade dos mercados nacional e internacional. Neste panorama, já se teorizou que deve ocorrer um Estado Constitucional Democrático Cooperativo, que se articula em rede com 
agentes públicos e privados, nos contextos interno e internacional, como lecionou Peter Haberle (2003), atuando em uma rede de proteção aos direitos, garantias e deveres fundamentais do cidadão.

Um exemplo é a alocação de recursos públicos pela União, que tem o maior orçamento do Brasil, para o desenvolvimento de áreas essenciais como saúde, educação, segurança pública e cultura, tal como demonstra o gráfico abaixo.

\begin{tabular}{|c|c|c|c|c|c|c|}
\hline \begin{tabular}{c|} 
Ano \\
Exercicio
\end{tabular} & Funçäo (desc.) & Dotação Atual & Empenhado & Pago & RP Pago & Total Pago \\
\hline 2014 & 06 - Segurança Pública & $10.638 .076 .369,00$ & $8.945 .185 .298,87$ & 7.233.237.067,17 & $1.496 .751 .971,10$ & $8.729 .989 .038,27$ \\
\hline 2014 & 10 - Saúde & $100.313 .538 .371,00$ & $94.065 .346 .000,55$ & $86.327 .540 .676,13$ & $7.518 .600 .406,75$ & $93.846 .141 .082,88$ \\
\hline 2014 & 12 - Educação & 102.438.345.117,00 & $93.897 .290 .662,71$ & $80.903 .901 .144,69$ & $13.296 .878 .806,81$ & $94.200 .779 .951,50$ \\
\hline 2014 & 13 - Cultura & $3.051 .053 .656,00$ & $1.835 .787 .687,63$ & $908.005 .916,14$ & $627.042 .636,78$ & $1.535 .048 .552,92$ \\
\hline & Total 2014 & $216.441 .013 .513,00$ & 198.743.609.649,76 & 175.372.684.804,13 & 22.939.273.821,44 & 198.311.958.625,57 \\
\hline 2015 & 06 - Segurança Pública & 10.807.229.620,00 & $9.035 .951 .435,95$ & $7.753 .719 .483,82$ & $1.138 .256 .047,74$ & $8.891 .975 .531,56$ \\
\hline 2015 & 10 - Saúde & $113.007 .419 .766,00$ & 102.093.782.976,83 & 93.864.923.546,90 & $6.347 .319 .203,79$ & $242.750,69$ \\
\hline 2015 & 12 - Educação & 115.501.163.942,00 & $103.779 .651 .895,30$ & $88.600 .739 .991,53$ & $9.436 .931 .899,36$ & 98.03 \\
\hline 2015 & 13 - Cultura & $2.797 .362 .737,00$ & $1.867 .416 .088,67$ & $855.175 .441,96$ & $913.886 .102,00$ & 3,96 \\
\hline & Total 2015 & $242.113 .176 .065,00$ & 216.776.802.396,75 & 191.074.558.464,21 & 17.836.393.252,89 & 208.910.951.717,10 \\
\hline 2016 & 06 - Segurança Pública & 10.343.532.369,00 & $9.715 .492 .478,72$ & $8.423 .101 .067,63$ & $1.276 .066 .932,56$ & $9.699 .168 .000,19$ \\
\hline 2016 & 10 - Saúde & $112.333 .047 .757,00$ & 108.268.384.482,46 & $100.190 .605 .307,83$ & $8.536 .244 .819,32$ & $0.127,15$ \\
\hline 2016 & 12 - Educação & $109.900 .303 .710,00$ & 106.738.195.557,73 & $95.184 .512 .946,82$ & $13.911 .819 .367,51$ & 109.096 .3 \\
\hline 2016 & 13 - Cultura & $2.335 .013 .589,00$ & $1.939 .529 .497,35$ & $951.534 .715,35$ & $1.119 .226 .043,03$ & $2.070 .760 .758,38$ \\
\hline & Total 2016 & 234.911.897.425,00 & $226.661 .602 .016,26$ & 204.749.754.037,63 & 24.843.357.162,42 & 229.593.111.200,05 \\
\hline 2017 & 06 - Segurança Pública & $11.548 .518 .830,00$ & $10.860 .870 .233,63$ & $9.133 .214 .442,06$ & $1.020 .888 .956,16$ & $10.154 .103 .398,22$ \\
\hline 2017 & 10 - Saúde & $120.356 .455 .929,00$ & $117.602 .483 .172,47$ & $102.713 .827 .690,68$ & $6.446 .994 .008,69$ & $109.160 .821 .699,37$ \\
\hline 2017 & 12 - Educação & $115.111 .614 .994,00$ & $111.405 .469 .319,37$ & $101.815 .707 .371,61$ & $9.453 .255 .961,13$ & 111.268.963.332,74 \\
\hline 2017 & 13 - Cultura & $2.183 .255 .676,00$ & 1.904.144.069,80 & $1.020 .637 .184,93$ & $881.132 .545,55$ & $1.901 .769 .730,48$ \\
\hline & Total 2017 & $249.199 .845 .429,00$ & 241.772.966.795,27 & 214.683.386.689,28 & 17.802.271.471,53 & $232.485 .658 .160,81$ \\
\hline 2018 & 06 - Segurança Pública & $12.851 .324 .098,00$ & $12.498 .748 .754,98$ & $8.820 .453 .903,29$ & 1.398.865.925,98 & $10.219 .319 .829,27$ \\
\hline 2018 & 10 - Saúde & $121.864 .792 .265,00$ & $120.876 .845 .472,00$ & 108.179.162.954,58 & 12.445.288.288,95 & $120.624 .451 .243,53$ \\
\hline 2018 & 12 - Educação & $114.309 .381 .798,00$ & 112.236.392.167,94 & $95.590 .465 .024,47$ & $7.922 .570 .796,83$ & $103.513 .035 .821,30$ \\
\hline 2018 & 13 - Cultura & $2.102 .005 .530,00$ & $2.004 .483 .305,71$ & $988.669 .602,21$ & $913.456 .313,41$ & $1.902 .125 .915,62$ \\
\hline & Total 2018 & 251.127.503.691,00 & $247.616 .469 .700,63$ & $213.578 .751 .484,55$ & $22.680 .181 .325,17$ & $236.258 .932 .809,72$ \\
\hline & Total Geral & \begin{tabular}{|c|}
$1.193 .793 .436 .123,00$ \\
\end{tabular} & \begin{tabular}{|l|l|}
$131.571 .450 .558,67$ \\
\end{tabular} & $\mid 999.459 .135 .479,80$ & \begin{tabular}{|l|}
$106.101 .477 .033,45$ \\
\end{tabular} & $1.105 .560 .612 .513,25$ \\
\hline
\end{tabular}

Foram escolhidos para exame os direitos fundamentais cultura, educação, saúde e segurança pública, por caracterizarem os maiores orçamentos da União e por demonstrarem os admiráveis valores destinados, na casa dos milhões, e a sensação de falta de investimentos nestas áreas sensíveis.

Uma das considerações possíveis ao se analisar os dados constantes no quadro acima é que houve a aplicação de recursos, contudo há necessidade de revisão das técnicas de administração e gestão pública, principalmente pela óptica do princípio constitucional da eficiência previsto no caput do artigo 37 da Norma Ápice, já demonstrando que há um dever de se implantar boa gestão pública como se demonstrará adiante.

O dado sobre o investimento público, acima exposto, também corrobora a nossa posição acadêmica de que praticamente não há cidadãos que se oponham a uma boa governança pública, contudo, inegavelmente ainda há largos passos 
para que se efetive o dever constitucional de implementação desse modelo de gestão governamental.

Ademais, quanto ao referido quadro visualiza-se a diferença entre o valor indicado no orçamento e aquele realmente efetivado, demonstrando que há desarranjos institucionais que impedem a execução orçamentária, voltando-se à necessidade de racionalização dos procedimentos e da efetivação do dever jurídico à boa gestão pública.

Pressupõe-se que o Estado Democrático de Direito tem interpretação e hermenêutica próprias, voltadas para a efetivação dos direitos e garantias fundamentais e da própria Constituição, sendo que no presente texto se trata do direito, bem como do dever de implantação da boa governança pública, como meio de efetivar proteção social para as pessoas.

\subsection{0 dever fundamental e o Estado Democrático de Direito}

Uma noção bem difundida no Ocidente é que os direitos e garantias fundamentais são aqueles essenciais e positivados na Constituição de um país. Há uma farta plêiade de autores como Sarlet (2015), Flores (2009), Mendes (2012) e Carbonell (2005), que apontam as suas principais características, história e posição superior no ordenamento jurídico, reconhecendo que: "Los derechos fundamentales representan una de las decisiones básicas del constituyente a travês de la cual los principales valores éticos y políticos de una comunidade alcanzan expresión jurídica" (PÉREZ LUNO, 2010, p. 316).

Em síntese, os direitos fundamentais são proposições jurídicas, formadas por regras e princípios que operam por termos constitucionais no Brasil (art. 5으, §1ํํ) e têm aplicação imediata, ou seja, eles devem ser utilizados prontamente em situações concretas cotidianas, com ou sem intermediação legal. Contudo, "simétricos dos direitos fundamentais apresentam-se os deveres fundamentais quer dizer, as situações jurídicas de necessidade ou adstrição constitucionalmente estabelecidas", como lecionou Jorge Miranda (2000, p. 76).

Demarca-se que o Estado Democrático de Direito é formado, juridicamente, por proposições que se orientam tanto com direitos e garantias quanto por deveres fundamentais e legais. Através da interpretação dessas proposições é que se alinham as normas de origem estatal que regem a sociedade. Portanto, há uma constante crítica sobre a multiplicidade de direitos fundamentais, sua pouca efetividade no cotidiano e a ausência de um estatuto jurídico que referende os deveres fundamentais como documentou Gradvohl (2009), ou ainda, segundo a lição de José Nabais para quem: "Um desprezo que é visível, sobretudo, 
quando confrontado com a atenção constitucional e dogmática que, quer em termos extensivos quer em termos intensivos, tem sido dispensada aos direitos fundamentais" (NABAIS, 2000, p. 3). O que também é descrito na literatura sobre este assunto:

\begin{abstract}
Apesar de existir considerável literatura sobre deveres fundamentais, o tratamento jurídico que lhes é dado está longe de um tratamento minimamente comparável àquele dispensado aos direitos fundamentais. Esse fato sobressai especialmente diante da falta de identificação pelo constituinte de quais seriam os deveres fundamentais e da ausência de regime constitucional próprio. Tudo o que se desenvolveu até aqui nesta revisão, pode-se considerar como um esforço em torno da construção de um regime desse tipo, da identificação da natureza e da formulação de um conceito, com o intuito de melhor compreender o tema dos deveres fundamentais. (SILVEIRA, 2016, p. 12)
\end{abstract}

Os deveres fundamentais são imposições jurídicas como solidariedade ambiental, proteção ao consumidor, obrigatoriedade de educação na educação básica e a imposição de subordinação à função social da propriedade privada, ou uma decorrência lógica do amparo aos direitos fundamentais, por exemplo, a necessidade de investimentos estatais em direitos sociais, tal como se infere no seguinte julgado do Supremo Tribunal Federal:

A Lei 7.844/1992 do Estado de São Paulo. Meia entrada assegurada aos estudantes regularmente matriculados em estabelecimentos de ensino. Ingresso em casas de diversão, esporte, cultura e lazer. [...] A livre iniciativa é expressão de liberdade titulada não apenas pela empresa mas também pelo trabalho. Por isso a Constituição, ao contemplá-la, cogita também da "iniciativa do Estado"; não a privilegia, portanto, como bem pertinente apenas à empresa. Se de um lado a Constituição assegura a livre iniciativa, de outro determina ao Estado a adoção de todas as providências tendentes a garantir o efetivo exercício do direito à educação, à cultura e ao desporto (arts. 23, V; 205; 208; 215; e 217, §3ำ, da Constituição). Na composição entre esses princípios e regras, há de ser preservado o interesse da coletividade, interesse público primário. 0 direito ao acesso à cultura, ao esporte e ao lazer são meios de complementar a formação dos estudantes (STF, 2018, p. 24)

Destarte, ao determinar que o Estado "adote providências" está se impondo um dever de atuação, ou seja, do direito fundamental que fixou uma obrigação estatal. Cabe a lembrança histórica de que: "já houve tempo em que os deveres fundamentais foram considerados como categoria jurídica de igual dignidade 
a direitos fundamentais" (CANOTILHO, 2014, p. 531). Há também a seguinte posição doutrinária:

Apesar de o conceito de dever ser originariamente um conceito moral, seu uso no âmbito jurídico está consolidado, fato o qual revela uma conexão entre Direito e Moral, o que enveredaria a análise para o campo da Filosofia Moral e desvirtuaria a proposta. Portanto, afasta-se a explicação etimológica, adotando-se, então, como ponto de partida o seguinte: tanto deveres quanto obrigações são condutas determinadas por normas jurídicas (SIQUEIRA, 2016, p. 3).

Entretanto, de forma diferente dos direitos, os deveres fundamentais não são autoaplicáveis e necessitam de regulamentação infraconstitucional, já que limitam a atuação dos cidadãos e da própria Administração Pública, compreendendo-se dessa maneira a regra hermenêutica de que restrições são interpretadas com as reservas cabiveis, ou ainda, segundo a doutrina constitucionalista portuguesa, "As normas consagradoras de deveres fundamentais reconduzem-se, pois, à categoria de normas desprovidas de determinabilidade jurídico-constitucional, e, por isso, carecem de mediação legislativa" (CANOTILHO, 2014, p. 535).

Um ponto que se destaca é sobre a aplicabilidade e destinação dos deveres fundamentais, havendo uma confusão conceitual sobre a sua utilização por todas as pessoas, já que os direitos essenciais possuem uma dimensão objetiva e outra subjetiva, tal como doutrinou Sarlet (2015). Esta celeuma pode ser respondida pela seguinte proposição doutrinária:

O mais importante e, ao mesmo tempo, mais polêmico são os deveres dos próprios titulares, entendendo os direitos fundamentais não só como posições ou direitos subjetivos, mas também como direitos deveres: todo direito fundamental gera uma obrigação de utilização e de exercício adequado ou para fins lícitos (SAMPAIO, 2013, p. 593).

Por conseguinte, há de se reconhecer que os deveres estão ao lado dos direitos fundamentais e têm a mesma hierarquia, sendo ambas as matrizes de criação de normas jurídicas, como exemplo, o dever de construção de uma boa governança pública, não se olvidando que: "o dever de eficiência dos administradores públicos reside na necessidade de tornar cada vez mais qualitativa a atividade administrativa", como lecionou Carvalho Filho (2018, p. 70), bem como se demonstrará a seguir. 


\section{A necessidade de efetivação do dever fundamental de implementação de uma boa governança pública}

Segundo dados da Organização das Nações Unidas (ONU), por causa de atos de ilicitude, como a corrupção, o mundo perde aproximadamente $5 \%$ do Produto Interno Bruto (PIB) dos países, que, de forma sintética, é a produção e vendas de produtos pelos Estados, sendo que estes valores: "chegam a mais de 2,6 trilhões de dólares por ano” (ONU/BR, 2018, p.1). Neste sentido, são desviados recursos que poderiam proporcionar a concretização de direitos humanos e fundamentais para situações gravíssimas, por exemplo, a atual crise internacional dos refugiados.

Apesar de um amplo espectro de dispositivos constitucionais com previsões expressas e implícitas sobre a Administração Pública, até mesmo com leis de combate a corrupção como a Lei no 8.429/1992, que dispõe sobre a responsabilização por atos de improbidade, e a Lei no- 12.846/2013, que possibilita a imposição de sanções às pessoas jurídicas que cometam atos de corrupção, entre tantas outras. A Federação da Indústria de São Paulo (FIESP), “aponta que o custo médio anual da corrupção no Brasil representa de 1,38\% a 2,3\% do Produto Interno Bruto (PIB), ou seja, gira em torno de R $\$$ R $\$ 41,5$ bilhões a R\$ 69,1 bilhões" (2018, p. 2). Isto posto, a sociedade brasileira é privada de acesso a escolas, hospitais e segurança pública por causa da apropriação de recursos de forma escusa por agentes públicos e privados que precisam ser controlados.

“A corrupção responde, todavia, por outras consequências mais controversas, no contexto do que se pode chamar de uma "economia da corrupção" (WARDE, 2018, p. 22). A percepção de corrupção no Brasil é tão alta que uma pesquisa global feita pela empresa de consultoria e auditoria Ernst \& Young (EY), entrevistando 2.550 executivos de 55 países, demostrou que $96 \%$ dos profissionais brasileiros entrevistados reconhecem que as práticas de suborno ou corrupção ocorrem amplamente nos negócios públicos e privados, sendo apontado como um problema crônico do Brasil, inclusive por aumentar consideravelmente o custo das obras públicas.

Não se deve olvidar também que a sensação de impunidade também já foi descrita como "teoria da graxa" (GOMES, 2018, p. 3), que consiste no reconhecimento de que em grandes negócios públicos e privados geralmente ocorre corrupção por motivações escusas. Mesmo a ação estatal foi descrita como “vampira ou cleptomaníaca”, como criticou Cristiano Campidelli (2018, p. 05), em alusão aos constantes ataques ao erário e aos particulares. Também por estes motivos tanto as esferas públicas e privadas como do terceiro setor necessitam 
implantar e constantemente aperfeiçoar práticas democráticas, de accountability, compliance e governança.

Para melhor entendimento salienta-se que o termo accountability coaduna a necessidade de responsabilização de todos os agentes públicos por suas ações no exercício de suas funções estatais. "Em outras palavras, é saber o que os agentes públicos estão fazendo, como estão fazendo, que consequências resultam das suas ações e como estão sendo responsabilizados" (ROCHA, 2009, p. 5).

O compliance é a adequação da gestão, pública ou privada aos instrumentos de controle interno e internacional, aperfeiçoando-as continuamente. Portanto, "estar em compliance é respeitar as leis e regulamentos internos e externos", tal como demonstraram Paes e Grazzioli (2018, p. 169).

Quanto à governança, destaca-se que é um termo polissêmico, com raízes históricas, com grandes influências internacional e nacional, que visam a melhorar as condições de realização das entidades públicas e privadas, já que ambas devem racionalizar seus processos. Em relação à governança pública se destaca a atuação do Tribunal de Contas da União, que em sua publicação Referencial Básico de Governança (2014) apresenta princípios deste instituto no contexto nacional: "transparência, equidade, prestação de contas e responsabilidade corporativa" (BRASILC). Ou ainda, conforme nota doutrinária:

\begin{abstract}
[...] governança pública pode ser entendida como a capacidade que os governos têm de: assegurar que a vontade dos cidadãos seja capturada nos planejamentos estratégicos, táticos e operacionais; selecionar pessoas e instituir normas e processos adequados para executaras ações planejada; articular a ação de todos os agentes públicos e privados, alcançar e controlar os resultados previstos, estabelecer indicadores de desempenho para verificar o quanto foi ou não foi alcançado e divulgar todas essas etapas a sociedade (NARDES, 2016, p. 177).
\end{abstract}

Salienta-se que accountability, compliance e governança são instrumentos que devem guiar as ações da Administração Pública, otimizando recursos, além de tornar cristalina a compreensão dos direitos, deveres e garantias fundamentais que a sociedade carece. A literatura demonstra que "a expressão governança surge, no tocante a gestão pública. Visando ao aprofundamento de condições que tornam um Estado eficiente" (MIRAGEM, 2013, p, 53), portanto, otimizam os recursos públicos em direitos, deveres, garantias e serviços públicos que devem ser disponibilizados para a sociedade.

Vale lembrar que em um ambiente de crise como foi descrito, com o aprofundamento da pobreza e exclusão social, é inadmissível que a Administração 
Pública não aplique a governança para racionalizar os recursos para a efetivação dos direitos fundamentais e construção da cidadania. O que se espera é que haja um Estado e consequentemente uma Administração Pública inteligente, tal como proposto por Matias-Pereira (2012). Fixa-se, preliminarmente, que a governança pública tem como suas principais funções normatizar, acompanhar e melhorar os relacionamentos entre os agentes públicos e também os contatos com a esfera privada, como exemplo, a celebração de contratos, como demonstrou o Tribunal de Contas da União (2014).

Ainda por causa dos constantes ataques ao erário, por agentes públicos e privados, no ano de 2017 o Brasil foi indicado para a 96o posição no ranking internacional de países com mais atos de corrupção, elaborado pela Transparência Internacional e divulgado pelo sítio eletrônico de notícias G1, como se exemplifica conforme a figura abaixo.

\section{Ranking da corrupção 2017 \\ Brasil caiu 17 posições. Quanto melhor a colocação, menos corrupto é considerado o país.}

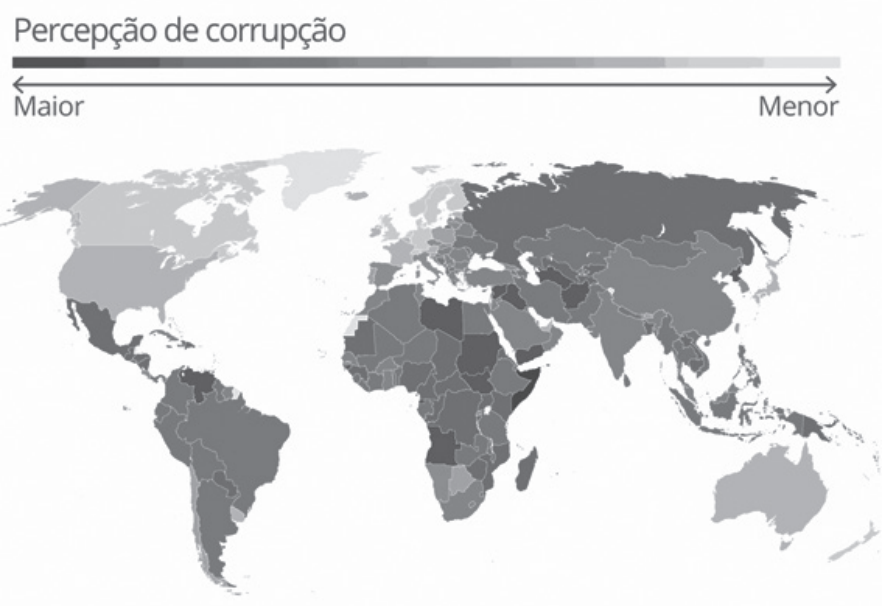

\section{Posição no ranking}

Nova Zelândia

Dinamarca

Finlândia

Noruega

\begin{tabular}{l}
91 Timor-Leste \\
96 Brasil \\
96 Colômbia \\
\hline 96 \\
Indonésia
\end{tabular}

177 Afeganistão

178 Síria

179 Sudão do Sul

180 Somália

Fonte: Índice de Percepção da Corrupção 2017 da Transparência Internacional 
Compreende-se que, apesar das constantes melhorias nos sistemas de controle interno e externo, ainda há um longo caminho para se construir uma Administração Pública e sociedade civil sem atos de improbidade ou corrupção. Observa-se aí o papel fundamental da academia em fomentar pesquisas sobre este assunto, além de apontar o dever de implantação de "boa governança" na gestão pública, já que: "A participação amplia a inclusão democrática, criando a percepção de maior justiça por parte da cidadania" (FILGUEIRAS, 2018, p. 80).

Esclarece-se que a expressão "boa governança" é utilizada nesta pesquisa em sinônimo de uma Administração Pública que cumpre todas as condições constitucionais e legais, devendo ser eficiente em sua função principal, que é efetivar os direitos, deveres e garantias dos cidadãos, além de relacionar suas ações com o Estado Democrático de Direito, já que: "a governança aplicada ao setor público vai promover desde as esferas locais, a institucionalização de mecanismos de participação no processo de tomada de decisões dos agentes públicos" (MIRAGEM, 2013, p, 53). Sendo esta, também, a posição do Tribunal de Contas da União (TCU) em publicação própria assim registrado:

Apesar do avanço que tais estruturas significam para a melhoria da capacidade de governança e gestão do Estado brasileiro, cabe reconhecer que para atender as demandas sociais é fundamental fortalecer ainda mais os mecanismos de governança como forma de reduzir o distanciamento entre Estado e sociedade (BRASILc, 2014, p. 16).

Não olvidamos que, do mesmo modo, Juarez Freitas realizou minucioso estudo sobre o direito fundamental “à boa administração pública” (2007, p. 20), gerando a conexão de que se há um direito subjetivo, há o dever estatal de realizar sua obrigação. De tal modo, uma das perspectivas para a atuação da academia seria a colaboração com os entes federados para fundamentar a posição sobre a necessidade de atuação do dever fundamental à boa governança pública. Desta maneira, as pesquisas, trabalhos acadêmicos e demais atividades de pesquisa poderiam influenciar a jurisprudência e os Poderes Executivo e Legislativo para que sejam tomadas providências concretas para a cristalização desta necessidade social.

Portanto, esta atuação poderia, por exemplo, indicar a necessidade de se evitar a incômoda situação generalizada de desvios ilegais de recursos públicos, que geram problemas de governabilidade que é o alinhamento político para o exercício da gestão pública e da governança.

Neste diapasão, a ação conjunta de órgãos de controle interno e externo, como os Tribunais de Contas e a participação da sociedade civil organizada, busca efetivar uma boa governança sintonizada com o Estado Democrático de Direito. 
Portanto, há uma relação lógica entre o direito do cidadão de receber os direitos fundamentais, e o dever de se efetivar uma boa governança pública como um "fim a ser buscado pelas administrações públicas, em todos os níveis, na concretização dos deveres postos pela ordem jurídica cogente, a resguardar, elementarmente, a autonomia dos entes que integram o pacto federativo nacional" (CORRALO, 2017, p. 179).

\section{Considerações finais}

Diante dos constantes problemas que o Brasil enfrenta, questiona-se se há um dever fundamental de se efetivar uma boa governança na Administração Pública. Para tanto, foi utilizado o método hipotético dedutivo, alinhado às técnicas de revisão bibliográfica e estudo de caso.

Atualmente, graves crises econômica, financeira, social e política ocorrem tanto no Brasil quanto no mundo. Nesta perspectiva, a atuação da academia é de fundamental importância no sentido de apresentar à sociedade suas contribuições, que têm sido bastante relevantes para o desenvolvimento e crescimento científico brasileiro, (re)visitando os conceitos de Estado e Administração Pública com intuito de auxiliar no alinhamento necessário para que haja a efetivação dos direitos, garantias e deveres fundamentais, no contexto dos desafios modernos em que um quarto da população brasileira vive na linha de pobreza, isto é, mais de cinquenta milhões de pessoas que não têm acesso a condições básicas.

Destarte, este trabalho acadêmico apresenta a necessidade de aplicar o conceito de dever jurídico estatal para a implementação da boa governança pública, que conceitualmente é aquela que cumpre os requisitos constitucionais e legais, absorvendo os parâmetros de accountability, compliance e governança pública. Inicialmente, demonstrou-se sinteticamente a evolução estatal do Ocidente, analisando os principais fundamentos do Absolutismo, Estado Liberal, Social e Democrático de Direito, ressalvando que não houve uma construção linear, mas gradual e fulcrada na necessidade de cada momento histórico.

Em seguida, foram explanadas as bases doutrinárias dos direitos fundamentais e sua relevância no contexto brasileiro atual, deixando fixada a noção de que eles possuem a mais alta hierarquia no ordenamento jurídico de um país, sendo considerados essenciais. A relevância dos direitos fundamentais foi corroborada também pelos dados do Sistema Integrado de Planejamento e Orçamento (SIOP) sobre a indicação e execução orçamentária dos valores investidos em cultura, educação, saúde e segurança pública, demonstrando que a União tem utilizado vultosos recursos. Contudo ainda há um déficit na prestação de serviços 
públicos, deixando a sensação de que é necessário investir na administração e gestão públicas.

0 percurso do presente trabalho foi antevisto para que se apontassem as principais pesquisas sobre o instituto jurídico denominado dever fundamental, ou seja, um conjunto de proposições jurídicas que normatizam as obrigações pessoais ou estatais, que buscam a concretização dos direitos e garantias fundamentais. Constatou-se que apesar de todos os direitos possuírem uma dimensão objetiva e outra subjetiva, há uma considerável desconsideração pelos deveres constitucionais e legais. Foi assentado ainda que os deveres fundamentais tenham a mesma hierarquia dos direitos e garantias previstos na Constituição e que devem ser observados no contexto da aplicação do Direito. Salientandose que por se tratar de uma restrição ao comportamento pessoal ou estatal é necessária uma regulamentação expressa de cada dever jurídico.

Por fim, foram apresentadas pesquisas nacionais e internacionais que demonstram que a corrupção é um fenômeno mundial, que desvia recursos na casa dos trilhões de reais no plano global, alijando as pessoas de escolas, hospitais, segurança pública, entre outros serviços prestados pela Administração Pública. Assim, é necessária a aplicação do dever jurídico de concretização da boa gestão pública para que haja a cristalização dos direitos e garantias fundamentais, tendo em vista que já não há mais dúvida de que os princípios do accountability, compliance e governança encontram-se em prol da promoção dos serviços públicos que são prestados à sociedade.

\title{
The need to effective the constitutional good public governance in the current brazilian Democratic State of Law
}

\begin{abstract}
The research problem faced in this academic paper is: is there a fundamental duty to implement Good Public Governance in Brazil? The discussion was based on the hypothetical-deductive method and based on the scientific techniques of the bibliographic review and case study, in the academic article elaborated, aimed to demonstrate the need to apply the legal duty to implement Good Public aegis of the current paradigm of the Democratic State of Law. For that, the evolution of the rule of law, liberal and social, to the parameter that is still under construction was evidenced. Then the difference between the fundamental rights and duties was pointed out and, finally, the structural problems of corruption that prevented the crystallization of the essential rights were explained. The conclusion drawn from doctrinal lessons and real cases is that it is necessary to adopt criteria that improve the provision of public services in Brazil.
\end{abstract}

Keywords: Good public management. Fundamental duties. Democratic State of Law.

Summary: 1 Introduction - 2 Democratic State of Law: changes, duties and challenges - 2.1 The fundamental obligation and the Democratic State of Law - $\mathbf{3}$ The need of establishment of the fundamental duty of implementation of good public governance $\mathbf{-} \mathbf{4}$ Final considerations - References 


\section{Referências}

ARRUDA NETO, Pedro Thomé de. Direito das Políticas Públicas. Belo Horizonte: Fórum, 2015. BAUMAN, Zigmunt. Comunidade: a busca por segurança no mundo atual. Trad. Plínio Dentzien. Rio de Janeiro: Zahar, 2003.

BAUMAN, Zigmunt. Estado de Crise. Trad. Renato Aguiar. Rio de Janeiro: Zahar, 2016.

BAUMAN, Zigmunt. Globalização: as consequências humanas. Trad. Marcus Penchel. Rio de Janeiro: Zahar, 1999.

BAUMAN, Zigmunt. Modernidade Líquida. Trad. Plínio Dentzien. Rio de Janeiro: Zahar, 2001

BRASIL, Constituição da República Federativa do Brasil. Disponível em: http://www.planalto. gov.br/ccivil_03/Constituicao/Constituicao.htm. Acesso em: 3 jan. 2019.

CANOTILHO, Joaquim J. Gomes. Direito Constitucional e Teoria da Constituição. 7. ed. Coimbra: Almedina, 2014.

CAMPIDELLI, Cristiano. Teoria da graxa sobre rodas, teoria do Estado vampiro e teoria da exceção de Romeu e Julieta. Disponível em: https://ccampidelli.jusbrasil.com.br/ artigos/590426013/teoria-da-graxa-sobre-rodas-teoria-do-estado-vampiro-e-teoria-da-excecaode-romeu-e-julieta. Acesso em: 3 jan. 2019.

CARBONELL, Miguel. Una História de Los Derechos Fundamentales. Buenos Aires: UNAN, 2005.

CARVALHO FILHO, José dos Santos. Manual de Direito Administrativo. 32. ed. São Paulo: Atlas, 2018

CATTONI, Marcelo. Direito Constitucional. Belo Horizonte: Mandamentos, 2002.

CONDE, Enrique Álvarez; AUSINA, Rosario Tur. Derecho Constitucional. 4. ed. Madrid: Tecnos, 2014.

CORRALO, Giovani da Silva. Há um Direito Fundamental à Boa Governança? In: Joaçaba, v. 18, n. 1, p. 165-184, jan./abr. 2017.

CREVELD, Martin van. Ascensão e declínio do Estado. São Paulo: Martins Fontes, 2004.

FILGUEIRAS, Fernando. Indo além do gerencial: a agenda da governança democrática e a mudança silenciada no Brasil. In: Revista da Administração Pública - RAP. Rio de Janeiro 52 (1):71-88, jan. - fev. 2018.

FLORES, Joaquín Herrera. Teoria Crítica dos Direitos Humanos: os direitos humanos como produtos culturais. Rio de Janeiro: Lumen Juris, 2009.

FREITAS, Juarez. Discricionariedade Administrativa e o Direito Fundamental à Boa Administração Pública. São Paulo: Malheiros, 2007.

GOMES, Diego. A corrupção enquanto fenômeno social: elemento pernicioso nas estruturas estatais ou graxa sobre as roas da economia? In: Revista de Doutrina e Jurisprudência. 53. Brasília. 109 (2). p. 159-172 / jan.-jun., 2018. 
GRADVOLHL, Michel André Bezerra Lima. Deveres Fundamentais: Conceito, Estrutura e Regime. Disponivel em: https://docplayer.com.br/22743212-Deveres-fundamentais-conceitoestrutura-e-regime.html. Acesso em: 3 jan. 2019.

HABERLE, Peter. Nove Ensaios constitucionais e uma aula de jubileu. São Paulo: Saraiva, 2012.

HABERLE, Peter. El Estado Constitucional. Ciudad del México: Universidad Nacional Autónoma de México, 2003.

HORTA, José Luiz Borges. História do Estado de Direito. São Paulo: Alameda, 2011.

HORTA, José Luiz Borges; SALGADO, Karine. História, Estado e Idealismo Alemão. Belo Horizonte: Editora UFMG, 2017.

INSTITUTO BRASILEIRO DE GEOGRAFIA E ESTATÍSTICA (IBGE). Disponível em: http://www. ipea.gov.br/agencia/images/stories/PDFs/livros/03.renda.pdf. Acesso em: 3 jan. 2019.

KUHN, Thomas S. A estrutura das revoluções científicas. 5. ed. São Paulo: Editora Perspectiva, 1997.

MATIAS-PEREIRA, José. Finanças Públicas: Foco na Política Fiscal, no Planejamento e Orçamento Público. 6. ed. São Paulo: Atlas, 2012.

MENDES, Gilmar Ferreira. Direitos Fundamentais e Controle de Constitucionalidade: Estudos de direito constitucional. 4. ed. São Paulo: Saraiva, 2012.

MIRAGEM, Bruno. A nova Administração Pública e o Direito Administrativo. 2. ed. São Paulo: RT, 2013.

MIRANDA, Jorge. Teoria do Estado e da Constituição. 2. ed. São Paulo, Forense, 2009.

MIRANDA, Jorge. Manual de Direito Constitucional: Direitos Fundamentais. 3. ed. Coimbra: Coimbra Editora, 2000, Tomo IV.

MOUNK, Yascha. O povo contra a democracia: por que nossa liberdade corre perigo e como salvá-la. São Paulo: Cia das Letras, 2019

NABAIS, José Casalta. A face oculta dos direitos fundamentais: os deveres e os custos dos direitos. In: Revista Direito Mackenzie, São Paulo, ano 3, n. 2, p. 9-30, 2000.

NARDES, João Augusto Ribeiro. Governança Pública: o desafio do Brasil. 2. ed. Belo Horizonte, Fórum, 2016.

ONU/BR, Corrupção custa mais de US\$ 2,6 trilhões por ano, alerta PNUD. Disponível em: https://nacoesunidas.org/corrupcao-custa-mais-de-us-26-trilhoes-por-ano-alerta-pnud/. Acesso em: 3 jan. 2019

PAES, José Eduardo Sabo; GRAZZIOLI, Airton. Compliance no Terceiro Setor: Controle e Integridade nas Organizações da Sociedade Civil. São Paulo: Elevação, 2018.

ROCHA, Arlindo Carvalho. Accountability na Administração Pública: a Atuação dos Tribunais de Contas. In: XXXIII Encontro Nacional da ANPAD, São Paulo: set. 2009.

SAMPAIO, José Adércio Leite. Teoria da Constituição e dos Direitos Fundamentais. Belo Horizonte: Del Rey, 2013. 
SARLET, Ingo Wolfgang. A eficácia dos Direitos Fundamentais: uma teoria geral dos direitos fundamentais na perspectiva constitucional. 12. ed. Porto Alegre: 2015.

SCHMITT, Carl. Teoría de la Constituición. Madrid: Tecnos 1975, v. VIII.

SILVA, José Afonso da Silva. Teoria do Conhecimento Constitucional. São Paulo: Malheiros, 2014.

SILVA, Christiane Oliveira Peter da. Transjusfundamentalidade: Diálogo Transnacionais sobre Direitos Fundamentais. Curitiba: Editora CRV, 2015.

SIQUEIRA, Júlio Pinheiro Faro Homem de. Elementos para uma teoria dos deveres fundamentais: uma perspectiva jurídica. In: Revista de Direito Constitucional e Internacional RDCl. v. 95, abr.jun., 2016.

SOUZA JUNIOR, José Geraldo de. (Org.). Sociedade democrática, direito público e controle externo. Brasília, Tribunal de Contas, 2006.

SUPREMO TRIBUNAL FEDERAL. Ação Direita de Inconstitucionalidade (ADI) no. 1960. Disponível em: http://www.stf.jus.br/portal/constituicao/artigo.asp\#ctx1. Acesso em: 3 jan. 2019.

TRIBUNAL DE CONTAS DA UNIÃO. Referencial básico de governança aplicável a órgãos e entidades da administração pública. Versão 2 - Brasília: TCU, Secretaria de Planejamento, Governança e Gestão, 2014.

WARDE, Walfrido. O espetáculo da corrupção: como um sistema corrupto e o modo de combatê-lo estão destruindo o país. Rio de Janeiro: LeYa, 2018.

VIII FESTIVAL de poesia de Medellin. Thiago de Mello (Brasil) em 1998. Faz Escuro Mas Eu Canto. Disponível em: http:// www.festivaldepoesiademedellin.org/pub.php/es/Festival/ Historia/índex.htm. Acesso em: 3 jan. 2019

Informação bibliográfica deste texto, conforme a NBR 6023:2018 da Associação Brasileira de Normas Técnicas (ABNT):

PAES, José Eduardo Sabo; AGUIAR, Severiano José Costandrade de; SANTOS, Júlio Edstron S. A necessidade de se efetivar o dever constitucional à boa governança pública no atual Estado Democrático de Direito brasileiro. Direitos Fundamentais \& Justiça, Belo Horizonte, ano 13, n. 40, p. 199-220, jan./jun. 2019.

Recebido em: 05.06.2018

Pareceres: 14.10.2018, 15.10.2018 e 22.02.2019 Aceito para publicação: 26.02.2019 